\title{
Effect of Temperature on the Killing of Opisthorchis viverrini Eggs In Vitro
}

\author{
Parichart Boueroy ${ }^{1,2,3}$, Kunyarat Duenngai ${ }^{3,4}$, Chatanun Eamudomkarn', Panupan Sripan ${ }^{1,2,3}$, \\ Thidarut Boonmars ${ }^{1,2,3, *}$, Benjamabhorn Pumhirunroj ${ }^{1,2,3}$, Atchara Artchayasawat ${ }^{1,2}$, Jiraporn Songsri ${ }^{1,2,3}$, \\ Kanpicha Chomphumee ${ }^{3}$, Panaratana Rattanasuwan ${ }^{5}$, Porntip Laummaunwai ${ }^{1,2}$, \\ Sukhonthip Khueangchiangkhwang ${ }^{1,2,3}$, Sirintip Boonjaraspinyo ${ }^{6}$

\begin{abstract}
${ }^{1}$ Department of Parasitology, Faculty of Medicine, Khon Kaen University, Khon Kaen 40002, Thailand; ' $N$ Neglected, zoonosis, and vector-borne disease group, Faculty of Medicine, Khon Kaen University, Khon Kaen 40002, Thailand; ' $L i v e r$ Fluke and Cholangiocarcinoma Research Institute, Khon Kaen University, Khon Kaen 40002, Thailand; ${ }^{4}$ Department of Public Health, Faculty of Science and Technology, Phetchabun Rajabhat University, Phetchabun 67000, Thailand; ${ }^{5}$ Department of Anesthesiology, Faculty of Medicine, Khon Kaen University, Khon Kaen 40002, Thailand; ${ }^{6}$ Department of Community Medicine, Faculty of Medicine, Khon Kaen University, Khon Kaen 40002, Thailand
\end{abstract}

\begin{abstract}
Contaminated liver fluke egg in the environment has led to the high prevalence of human opisthorchiasis associated with cholangiocarcinoma in Southeast Asia. To find the effective lessening methods of Opisthorchis viverrini eggs in the contaminated environment, we investigated the temperature conditions for killing of these trematode eggs in vitro. Numerous 0 . viverrini eggs were obtained in the proximal part of uteri of adult worms from experimental hamsters. Mature eggs with miracidium were allocated by experimental groups ( 2 control: positive and negative and 4 treatment: 50 , 60,70 , and $80^{\circ} \mathrm{C}$ ) with $0.85 \%$ saline, and treated by the experimental plan. Eggs in each experimental groups were observed under the confocal microscope after stain with Propidium lodide (PI) to evaluate the effect of temperatures. Eggs in 70 and $80^{\circ} \mathrm{C}$ groups were all killed after over 10 min heated. Majority of eggs in $60^{\circ} \mathrm{C}(10,15$, and 30 min heated), 70 and $80^{\circ} \mathrm{C}\left(5 \mathrm{~min}\right.$ heated) groups were inactivated. However in $50^{\circ} \mathrm{C}$ group, below half of eggs were to be killed in all time lapse (10, 15 and $30 \mathrm{~min})$. In order to prevent $O$. viverrini infection and cholangiocarcinoma, direct treatment of sewage by heating at 70 or $80^{\circ} \mathrm{C}$ at least $10 \mathrm{~min}$ is essential. Therefore, treatment of $O$. viverrini eggs at a high temperature is a potential method for controlling egg contamination in sewage.
\end{abstract}

Key words: Opisthorchis viverrini, egg, heating, temperature, treatment

It has been estimated that more than 40 million people are infected with foodborne trematodes [1]. In Thailand, the highest prevalence of liver fluke, Opisthorchis viverrini, is found in the northeastern region, associated with a high incidence of cholangiocarcinoma (CCA) [2]. Opisthorchiasis, O. viverrini infection, is a major public health problem in Southeast Asian countries including Laos, Cambodia, Vietnam, and Thailand [3-6]. In case of Thailand, it has been estimated that about 9 million peoples are to be infected with this endemic liver fluke. Especially, the prevalences (egg positive rates) were recorded to be $19.3 \%$ and $15.7 \%$ in residents of the north and northeastern regions respectively $[7,8]$. The annual economic

\footnotetext{
- Received 28 July 2018, revised 2 January 2019, accepted 13 January 2019.

*Corresponding author (bthida@kku.ac.th; boonmars@yahoo.com)

(C) 2019, Korean Society for Parasitology and Tropical Medicine

This is an Open Access article distributed under the terms of the Creative Commons Attribution Non-Commercial License (http://creativecommons.org/licenses/by-nc/4.0) which permits unrestricted non-commercial use, distribution, and reproduction in any medium, provided the original work is properly cited.
}

loss due to opisthorchiasis and CCA is estimated about 120 million US dollars for medical cost and loss of labor in Thailand [9].

The eggs of $O$. viverrini can contaminate the environment as a result of lack of hygienic defecating habits or the use of human feces for fertilizer (night soil) [10]. One of the risk factors in opisthorchiasis is egg contaminations by reservoir hosts such as dogs, cats and wild animals as well as humans in the ecosystem of $O$. viverrini. Numerous studies on the infection status with this liver fluke have been reported in cats and dogs from Lao PDR and Thailand. The prevalences (egg positive rates) in fecal samples of dogs in Lao PDR were recorded 20$36 \%$ [11-13], and those of dogs and cats from Thailand were $3.9 \%$ and $36.4 \%$ respectively [14]. The higher endemicity of opisthorchiasis in the definitive hosts, i.e., human, cat and dog, contribute to the persistent maintaining of life cycle of this liver fluke in endemic areas. Therefore, it is important to find effective methods for the interruption of viable eggs con- 
tamination in the environment. The photosensitized porphyrin, an environment-friendly photoactive compound, was previously used to remove of helminth eggs in wastewater, and showed $90.0 \%$ remove efficiency [15]. The natural coagulant, seed extract of Moringa oleifera, was experimentally adopted to decrease the viability of helminth eggs in irrigation water [16]. However, the effective of the temperature for the killing of Opisthorchis viverrini eggs contaminated in the environment has not been reported yet.

To control the O. viverrini, there is the need to cut it life cycle in each step; i) eating cooked fish seems to be very simple and easy, in fact it is too difficult to change the eating culture in this region [17], ii) using good diagnostic technique [18] and effective treatment of infected human and or reservoir hosts with praziquantel [19] and iii) good sewage sanitary management systems, even though this region is having the household sanitation tank, but remains a big problem of water reservoir contaminated with liver fluke egg, which evidenced the prevalence of $O$. viverrini infected fish. The treatment of the human fecal material to kill O. viverrini eggs might help to reduce the prevalence of this parasite. We, therefore, expected to cut the life cycle of $O$. viverrini by destroying its egg in the fecal specimen using a heating method that may be used to design the sanitary tank management system. The objective of the study was to investigate the effects of temperature on the viability of $O$. viverrini eggs, and applied to treat the fecal specimen.

Adult O. viverrini were left over from another project (ACUCKKU-20/2559). The eggs of O. viverrini were obtained from uteri of adult worms, which were recovered from the biliary tract of hamster at 1 month after infection. Mature eggs with

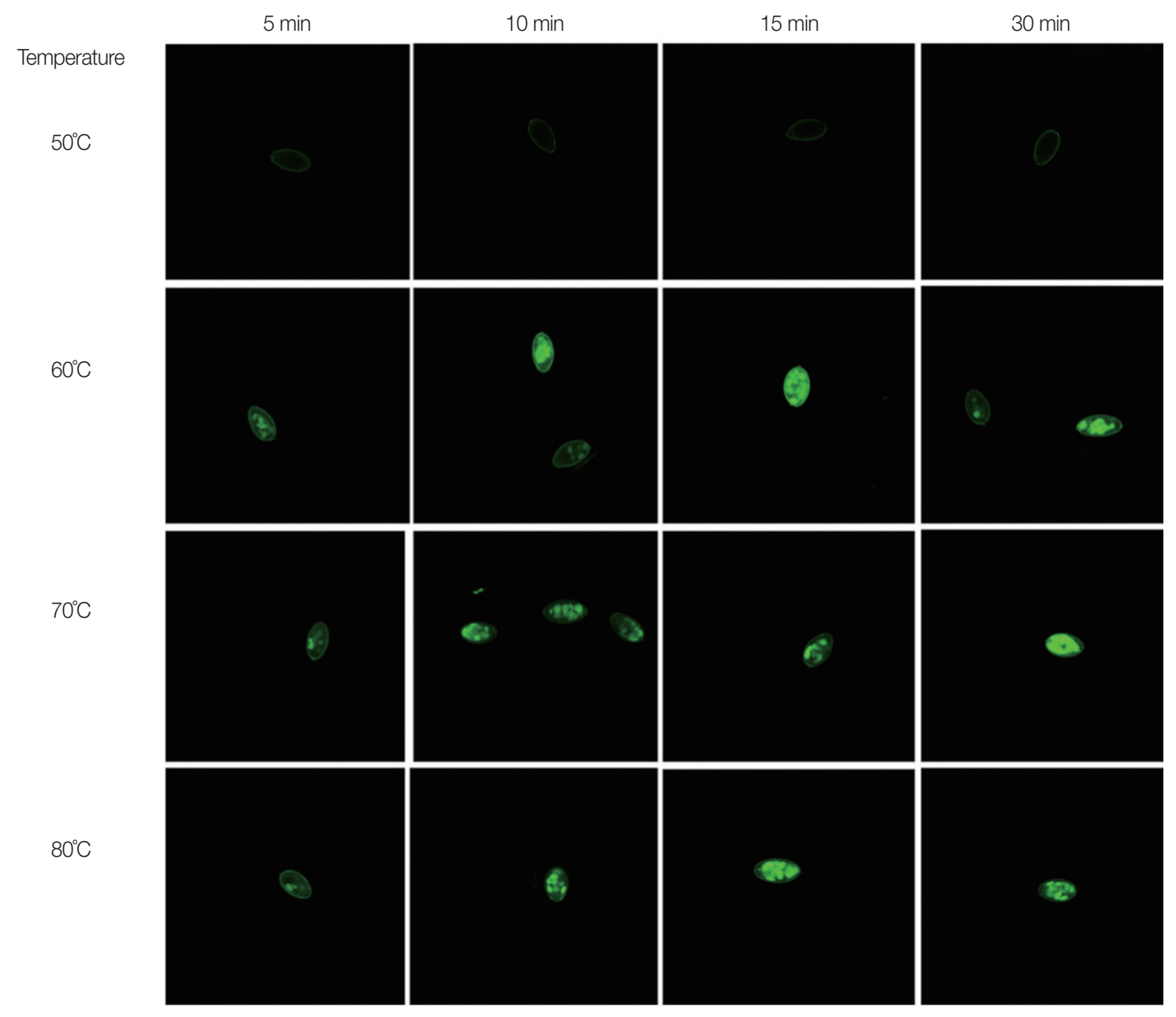

Fig. 1. Effect of temperature on viability of Opisthorchis viverrini eggs incubated at $50,60,70$, and $80^{\circ} \mathrm{C}$ for $5,10,15$, and 30 min. Eggs in each experimental groups were observed under the confocal microscope after stain with propidium iodide. PI cannot penetrate living eggs but produces intense green color in dead eggs. 
miracidium were collected under a stereomicroscope after incision of the proximal portion of uterus of adults. Eggs were divided into 3 groups, 2 control groups, and a treatment group. One control group was simply maintained in $0.85 \%$ saline at room temperature (negative control). The second control group consisted of eggs killed by autoclaving at $121^{\circ} \mathrm{C}$ (positive control). In the experimental group, batches of eggs in $0.85 \%$ saline were heated at $50,60,70$, and $80^{\circ} \mathrm{C}$ for 5,10 , $15,30 \mathrm{~min}$ in a thermal cycler machine respectively. Eggs from each treatment were incubated with propidium iodide (PI) $(0.5 \mathrm{mg} / \mathrm{ml})$ for $20 \mathrm{~min}$ at room temperature and then observed using a confocal microscope. PI is a fluorescence dye used to distinguish between viable and non-viable cells. The membranes of viable cells exclude this dye [20]. PI passes through damaged cell membranes and intercalates with nucleic acid (DNA or RNA) to stain nuclei of dead cells [20,21]. PI cannot penetrate living eggs but produces intense color in dead eggs. A separate group of eggs (positive control) was killed by autoclaving to confirm that PI could stain dead eggs. Statistical analyses were performed using SPSS version 16 software (SPSS Inc., Chicago, Illinois, USA). All data are expressed as mean \pm standard deviation (SD).

At 70 and $80^{\circ} \mathrm{C}, 100 \%$ of $O$. viverrini eggs were dead after 10 min of incubation (Figs. 1, 2). Eggs in 60 (5, 10, 15, and 30 $\mathrm{min}), 70(5 \mathrm{~min})$, and $80^{\circ} \mathrm{C}$ groups ( $5 \mathrm{~min}$ ) groups were killed more than $50 \%$ (Figs. 1, 2). However, at $50^{\circ} \mathrm{C}$ heated, O. viverrini eggs were killed less than 50\% after treated for 10, 15, 30 min.

The food-borne trematode O. viverrini is the major public health problem in Southeast Asia, such as Lao PDR and Thailand [3]. Peoples get infected by eating raw or under cooked freshwater fish contaminated with metacercariae. The poor hygienic defecation into the fields that are being washed into water bodies (pond and lakes) during rainfall, causes transmission into freshwater snails $[22,23]$. In the northeast part of

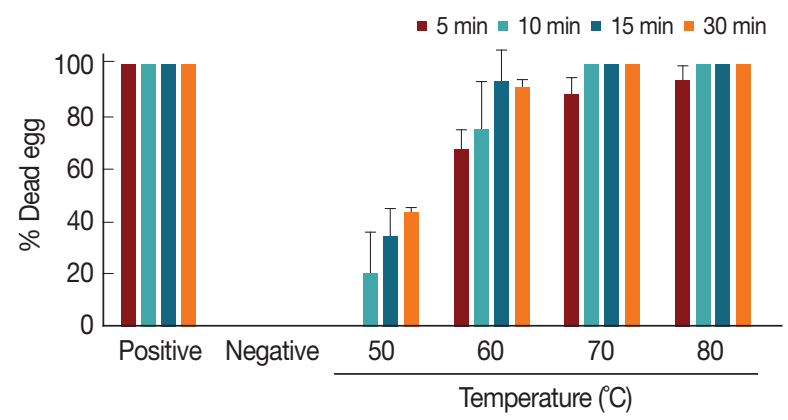

Fig. 2. Proportion of Opisthorchis viverrini eggs dead by heating.
Thailand, the collection and transport service of human excreta, $78 \%$ were collected by licensed private companies, $13 \%$ of unlicensed private companies, $9 \%$ of the municipalities. Surprisingly, only $4 \%$ of all disposal sites were good practice in the excreta disposal system [23].

The disposal system of fecal sludge by private vacuum-truck into public land, grassland, or orchard and rice fields was not appropriate [24,25]. Thus, this inappropriate disposal system of untreated fecal sludge into the different site can cause the transmission of pathogens leading to human diseases [24]. In addition, $10 \%$ of the population in developing countries are infected with intestinal worm by unsafe waste and human excreta management [26].

This present study is the first report to address the effects of heating on $O$. viverrini eggs with sanitation management in mind. The previous study found that eggs of Echinococcus multilocularis could be killed by ultra-cold temperature $\left(-70^{\circ} \mathrm{C}\right)$ and by rapid cooling in liquid nitrogen [27,28]. Eggs of Benedenia seriolae were killed by immersion in tap water at $50^{\circ} \mathrm{C}$ for $30 \mathrm{sec}$ [29].

The method of fecal sludge management in Thailand are, i) treatment before releases to the environment, ii) release to the environment via the transportation without treatment, and iii) release to the environment from the toilet. Our present studies suggest that the heating of fecal sludge is one of choices for the management of pathogens (bacteria, fungi and parasites) that contaminates the environment. Direct treatment of fecal sludge by heating at 70 or $80^{\circ} \mathrm{C}$ at least $10 \mathrm{~min}$ is essential to prevent $O$. viverrini infection. This method could be applied in all regions, even where there is no electricity. The energy sources for boiling the sewage are solar cell, gasoline, electric currents, and natural gas from fermented agriculture waste and so on.

However, this study was limited to investigate the effect of temperature on other parasite such as Ascaris lumbricoides eggs. It well known that a shell of 3 thick layers eggs of A. lumbricoides is the most durability against different chemical and environmental factors [30]. A. lumbricoides is pathogenic parasite that has been isolated in wastewater and use for indicator for unsafe drinking-water contaminated [31-33]. Thermal techniques can reduce enteric pathogen group including bacteria, viruses, and protozoa. However, treatment process by heating method is limited in spores, which are more resistant to thermal inactivation than are vegetative cells. The conventional disinfectant for treatment of household water treatment are chlorine, chlorine dioxide, ozone, peracetic acid. Moreover, UV radiation has been used for disinfection in wastewater treat- 
ment $[31,32]$.

In conclusion, heating at 70 and $80^{\circ} \mathrm{C}$ groups after 10,15 , and 30 min can kill $O$. viverrini eggs. This study suggests that destroying the Opisthorchis viverrini eggs in feces using heat is a possible approach for controlling egg contamination in the environment. This technique can be used for household toilet or sanitation tank management. This information may useful for implementation in endemic areas to prevent opisthorchiasis and cholangiocarcinoma in the future.

\section{ACKNOWLEDGMENTS}

This study was supported by the Cholangiocarcinoma Screening and Care Program: CASCAP (Thailand Grand Challenges: Fluke-Free Thailand) (CARI 05/2560), invitation research (IN61125) and Thailand Research Fund (RTA5580004), Faculty of Medicine, Khon Kaen University. This research was supported by the Post-Doctoral Program from Research Affairs and Graduate School, Khon Kaen University (no. 58441).

\section{CONFLICT OF INTEREST}

We have no conflict of interest related to this work.

\section{REFERENCES}

1. Sripa B, Kaewkes S, Intapan PM, Maleewong W, Brindley PJ. Food-borne trematodiases in Southeast Asia: epidemiology, pathology, clinical manifestation and control. Adv Parasitol 2010; 72: 305-350.

2. Sripa B, Pairojkul C. Cholangiocarcinoma: lessons from Thailand. Curr Opin Gastroenterol 2008; 24: 349-356.

3. World Health Organization. Control of foodborne trematode infections. Report of a WHO Study Group. World Health Organ Tech Rep Ser 1995; 849: 1-157.

4. Kaewkes S. Taxonomy and biology of liver flukes. Acta Trop 2003; 88: 177-186.

5. Jongsuksuntigul $\mathrm{P}$, Imsomboon T. Opisthorchiasis control in Thailand. Acta Trop 2003; 88: 229-232.

6. Kobayashi J, Vannachone B, Sato Y, Manivong K, Nambanya S, Inthakone S. An epidemiological study on Opisthorchis viverrini infection in Lao villages. Southeast Asian J Trop Med Public Health 2000; 31: 128-132.

7. Yossepowitch O, Gotesman T, Assous M, Marva E, Zimlichman R, Dan M. Opisthorchiasis from imported raw fish. Emerg Infect Dis 2004; 10: 2122-2126.

8. Sithithaworn P, Haswell-Elkins M. Epidemiology of Opisthorchis viverrini. Acta Trop 2003; 88: 187-194.
9. Andrews RH, Sithithaworn P, Petney TN. Opisthorchis viverrini: an underestimated parasite in world health. Trends Parasitol 2008; 24; 497-501.

10. Fried B, Graczyk TK, Tamang L. Food-borne intestinal trematodiases in humans. Parasitol Res 2004; 93: 159-170.

11. Ditrich O, Scholz T, Giboda M. Occurrence of some medically important flukes (Trematoda: Opisthorchiidae and Heterophyidae) in Nam Ngum water reservoir, Laos. Southeast Asian J Trop Med Public Health 1990; 21: 482-488.

12. Scholtz T, Uhlírová $M$, Ditrich $\mathrm{O}$. Helminth parasites of cats from the Vientiane Province, Laos, as indicators of the occurrence of causative agents of human parasitosis. Parasite 2003; 10: 343-350.

13. Giboda M, Ditrich O, Scholz T, Viengsay T, Bouaphanh S. Current status of food-borne parasitic zoonoses in Laos. Southeast Asian J Trop Med Public Health 1991; 22 (suppl): 56-61.

14. Enes JE, Wages AJ, Malone JB, Tesana S. Prevalence of Opisthorchis viverrini infection in the canine and feline hosts in three villages, Khon Kaen Province, northeastern Thailand. Southeast Asian J Trop Med Public Health 2010; 41: 36.

15. Alouini Z, Jemli M. Destruction of helminth eggs by photosensitized porphyrin. J Environ Monit 2001; 3: 548-551.

16. Sengupta ME, Keraita B, Olsen A, Boateng OK, Thamsborg SM, Pálsdóttir GR, Dalsgaard A. Use of Moringa oleifera seed extracts to reduce helminth egg numbers and turbidity in irrigation water. Water Res 2012; 46: 3646-3656.

17. Grundy-Warr C, Andrews RH, Sithithaworn P, Petney TN, Sripa B, Laithavewat L, Ziegler AD. Raw attitudes, wetland cultures, lifecycles: socio-cultural dynamics relating to Opisthorchis viverrini in the Mekong Basin. Parasitol Int 2012; 61: 65-70.

18. Duenngai K, Sithithaworn P, Rudrappa UK, Iddya K, Laha T, Stensvold CR, Johansen MV. Improvement of PCR for detection of Opisthorchis viverrini DNA in human stool samples. J Clin Microbiol 2008; 46: 366-368.

19. Keiser J, Utzinger J. Chemotherapy for major food-borne trematodes: a review. Expert Opin Pharmacother 2004; 5: 1711-1726.

20. Sasaki DT, Dumas SE, Engleman EG. Discrimination of viable and non-viable cells using propidium iodide in two color immunofluorescence. Cytometry 1987; 8: 413-420.

21. Jones KH, Senft JA. An improved method to determine cell viability by simultaneous staining with fluorescein diacetate-propidium iodide. J Histochem Cytochem 1985; 33: 77-79.

22. Wykoff DE, Harinasuta C, Juttijudata P, Winn MM. Opisthorchis viverrini in Thailand: the life cycle and comparison with $O$. felineus. J Parasitol 1965; 51: 207-214.

23. Brockelman WY, Upatham ES, Viyanant V, Ardsungnoen S, Chantanawat R. Field studies on the transmission of the human liver fluke, Opisthorchis viverrini, in northeast Thailand: population changes of the snail intermediate host. Int J Parasitol 1986; 16: 545-552.

24. Suebsoh W, Charerntanyarak L. Municipal Human Excreta Management in northeast Thailand. Pak J Soc Sci 2009; 6: 376-381.

25. Schouw NL, Danteravanich S, Mosbeak H, Tjell JC. Composi- 
tion of human excreta-a case study from Southern Thailand. Sci Total Environ 2002; 286: 155-166.

26. Fewtrell L, Bartram J. Water Quality: Guidelines, Standards and Health. London, UK. IWA Publishing, World Health Organization. 2001.

27. Hildreth M, Blunt D, Oaks J. Lethal effects of freezing Echinococcus multilocularis eggs at ultralow temperatures. J Parasitol 2004; 90: 841-844.

28. Schiller EL. Studies on the helminth fauna of Alaska. XXVI. Some observations on the cold-resistance of eggs of Echinococcus sibiricensis Rausch and Schiller, 1954. J Parasitol 1955; 41: 578582.

29. Ernst I, Whittington I, Corneillie S, Talbot C. Effects of temperature, salinity, desiccation and chemical treatments on egg embryonation and hatching success of Benedenia seriolae (Monogenea:
Capsalidae), a parasite of farmed Seriola spp. J Fish Dis 2005; 28: 157-164.

30. Beyhan YE, Yilmaz H, Hokelek M. Effects of acetic acid on the viability of Ascaris lumbricoides eggs: Is vinegar reliable enough to clean the vegetables? Saudi Med J 2016; 37: 288.

31. World Health Organization. Guidelines for Drinking-Water Quality: Fourth Edition Incorporating the First Addendum. Geneva, Switzerland. World Health Organization. 2017.

32. Collivignarelli MC, Abbà A, Benigna I, Sorlini S, Torretta V. Overview of the Main Disinfection Processes for Wastewater and Drinking Water Treatment Plants. Sustainability 2017; 10: 86.

33. Arther RG, Fitzgerald PR, Fox JC. Parasite ova in anaerobically digested sludge. J Water Pollut Control Fed 1981; 53: 13341338. 
